\title{
Cosmology in the Philosophical Education of Ukraine: History and Modern Condition
}

\begin{abstract}
Sergii Rudenko
Doctor of Philosophy, Associate Professor, Taras Shevchenko National University of Kyiv (Kyiv, Ukraine)

E-mail: rudenkosrg@gmail.com

ORCID: 0000-0001-9069-0989

Yaroslav Sobolievskyi

$\mathrm{PhD}$, Assistant Professor, Taras Shevchenko National University of Kyiv (Kyiv, Ukraine)

E-mail: yasobolevsky@gmail.com

ORCID: 0000-0001-8251-2744

\section{Vadym Tytarenko}

$\mathrm{PhD}$, Assistant Professor, Taras Shevchenko National University of Kyiv (Kyiv, Ukraine) E-mail: tytarenko.vadym@gmail.com

ORCID: 0000-0001-9251-8859

The article is devoted to the philosophy of cosmology, its history and contemporary conditions, the tradition of studying and modern trends in teaching this discipline in higher education in Ukraine. There is problem of defining the subject of philosophy of cosmology, there are similar and different motifs with modern astrophysics, cosmology on the one hand, and, with the history of philosophy and modern philosophy on the other hand. The change in the subject of the philosophy of cosmology in the history of philosophy and science has been studied in this article. A modern state of the philosophy of cosmology in modern philosophical education is demonstrated.
\end{abstract}

Keywords: history of philosophy, cosmology, higher education, higher education of Ukraine.

Philosophy and Cosmology, Volume 20, 2018: 128-138

DOI: $10.29202 /$ phil-cosm/20/12

\section{Introduction}

In the $20^{\text {th }}$ century, cosmology has become a part of astronomy and thus from the field of philosophical disciplines passes into the ranks of the natural sciences. Ideas and views on the condition, development and possible scenarios of the further evolution of the Universe find the source of the reliability of knowledge in mathematics, physics and astrophysics, but at the

(C) Rudenko, Sergii, 2018

(C) Sobolievskyi, Yaroslav, 2018

(C) Tytarenko, Vadym, 2018 
same time, new discoveries in the natural sciences are increasingly in need of philosophical reflection, especially in the context of interdisciplinary. The main problem of philosophical cosmology is the definition of its subject matter. On the one hand, philosophical cosmology originates in antiquity from the comprehension of the cosmos, its nature and the place of man in it. There is an opinion that ancient philosophy and science went in different ways, mathematics and geometry being exact sciences was contrasted with physics and metaphysics, as sciences speculative. For more than two thousand years the ideas of cosmology were of a philosophical nature, reflections on the beginning and end of the Universe, the position of the Earth in space, the forces of interaction, and the nature of the heavenly bodies stirred the minds of the sages.

The definition of branch of philosophy named "philosophical cosmology" is used in this article as the synonym of the "philosophy of cosmology". The question of the boundaries between philosophy and science has been resolved long time ago It has been repeatedly stressed that modern philosophy does not represent natural philosophy or the "science of sciences," cannot and should not dictate natural science concepts and laws. Academician Vitaly Ginzburg once studied the question: What is the role of philosophy, astronomy and physics in solving the most pressing problem of cosmology - the choice of an adequate reality model of the universe? $\mathrm{He}$ cites as an example the controversy about the sphericity of the Earth and the heliocentric system. Criticism of heliocentric representations was not limited to references to Scripture and church dogmas, but was also conducted with certain empirical positions. In the article "How the universe works and how it develops in time" he wrote: "Common sense" summed up the English philosopher Francis Bacon. In 1622, he qualified the theory of Copernicus "as the speculation of a man who does not care about what fictions he introduces into nature, if only it answers his calculations" [Ginzburg, 1968]. Similarly, the physicist Hannes Alfven criticizes the "big bang" models as nonstationary cosmological models, but his ideas about the beginning of the Universe, according to Ginzburg, is the example of wrong philosophical analysis of the empirical data. However, one of the philosophical postulates says that the question of how and when matter arose is incorrect. Matter is eternal, it has always existed. The question of the beginning of the Universe is not a matter of science, but of a worldview. On the other hand, there are philosophical concepts that believe that matter is created by higher powers, which means that the question of the beginning of the Universe is exclusively philosophical. This testifies to the difference between scientific and the philosophical knowledge. The scientific approach to cosmology is associated with propositions of a limiting nature, philosophy is capable of simultaneously analyzing contradictory concepts, talking about infinite speeds and questions beyond time, looking for the meaning and purpose of scientific knowledge while preserving both physical and metaphysical. Rudolf Steiner (Rudolf Joseph Lonz Steiner, 1861-1925) noted in the series of reports "Cosmology, Religion and Philosophy": "Philosophy did not arise in the same way in which it is continued in modern times. In these days, it is a connection of ideas, which are not experienced in one's inner being, in the soul, in such a manner that a man, conscious of self, feels himself in these ideas as in a reality. Therefore, we seek after all possible theoretical means to prove that the philosophic content does refer to a reality. But this way leads only to different philosophic systems, and of these one can say they are right to a certain extent; for mostly the grounds on which they are refuted are of as much value as those on which it is sought to prove them" [Steiner, 1943].

An article is prepared in frames of scientific and research project "Modernization of Philosophical Education and Science of Ukraine on the basis of International Educational and Scientific Standards". Political and philosophical conditions of modern education and 
science development are representatively described in scientific papers by Volodymyr Khmil and Tetiana Khmil [Khmil, 2015; Khmil, 2016].

Article authors based their conclusions on the methodological ideas of Anatolii Malivskyi [Malivskyi, 2017] and Tatiana Danylova [Danylova, 2016] in the field of understanding of the anthropological dimensions and cosmological ideas development in the New Age and modern time.

\section{Historical change of the basic ideas and concepts of the philosophy of cosmology}

Early forms of cosmology were based on mythology, cosmogony and eschatological ideas of sages of different times, but subsequently there was a need for a rational justification of the phenomena of nature and reality. A feature of ancient cosmology was the idea of geocentrism according to this idea the Earth was placed in the center of the Cosmos. The Earth itself had a spherical shape, and there were moving heavenly bodies around it: the five planets, the Sun with the Moon and fixed sphere of stars. A great role in the development of philosophy of cosmology was played by the views of pre-Socratics, ancient natural philosophers who were looking for the cause of all things, seeing it sometimes in the elements, sometimes in the first theoretical construct, such as, for example, apeiron. They proposed a view of the Universe as an independent being, gave rise to a multitude of philosophical arguments for the inner regularity of the Universe.

The idea of Thales of Miletus ( $\Theta \alpha \lambda \tilde{\eta} \varsigma, 624-546 \mathrm{BC}$ ) was that the diversity of the material world comes from a simple element. This radically differed from the theological ideas about the origin of the world. The intuitive assumption turned out to be close to the views of modern science. The idea that everything comes from "water" was inherently philosophical in nature, but it found confirmation in natural science, which believes that in the beginning of the existence of the Universe there was a simple gas - hydrogen (which is part of the water). He was the founder of Greek philosophy and science. In Antiquity, space (cosmos) was perceived as sensual-concrete formation, and it is quite natural that its basis could be seen precisely in the elements that were sensually perceived by man. Accordingly, on the basis of sensory perception and through reflective thinking, concepts of the ontological design of being arose. If the fundamental questions of existence lie at the basis of the cosmos, then not physics, but metaphysics is capable of answering the question of the nature of being.

One of the first metaphysical concepts of the basis of being became Apeiron Anaximander

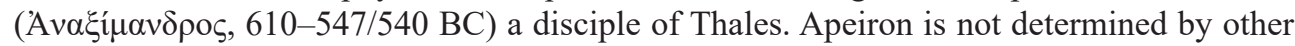
elements, it is a kind of universal whole. In his system of the Universe contained three revolutionary moments: a flat Earth is located without any support, the paths of celestial bodies are whole circles, and celestial bodies are at various distances from the Earth.

A further step in the studies was made by Pythagoras, who suggested that the Earth has the shape of a sphere. This hypothesis initially caused great resistance; among its opponents were the famous philosophers Anaxagoras, Empedocles, Leucippus, and Democritus. However, after its support by Parmenides, Plato, Eudox and Aristotle, the theory became the basis of mathematical astronomy and cosmology.

The search for simple beginnings for a complex Universe made Plato ( $\Pi \lambda \alpha \dot{\alpha} \omega \mathrm{v}, 428 / 427-$ $348 / 347 \mathrm{BC}$ ) to seek a solution to the mathematical problem, to compute the complex movements of the planets as the summed result of simple motions. Attempts to solve it were manifested in the theory of homocentric spheres (spheres with a single center) of Eudoxus of

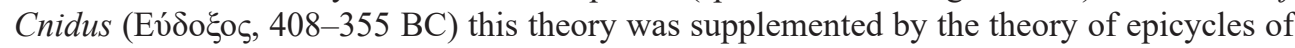




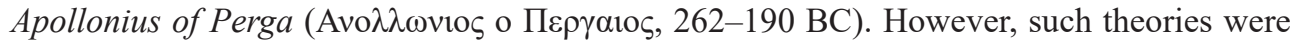
used mainly not to explain the processes in the Universe, but as a source of abstract reflection. The Greeks felt it was wrong to use mathematics in investigating the phenomena of reality, because the reality for them was an essential dimension, and it would take a long time before an attempt was made to look at nature; its book is written in the language of mathematics.

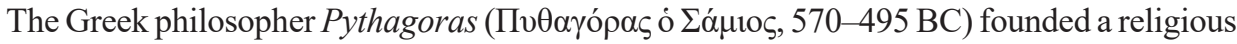
and philosophical union, unlike the Ionians, he and his disciples saw the foundation of the Universe in mathematical harmony, in the harmony of numbers, in the unity of science and religion. They considered the heavenly bodies to be gods. This was proved in the following way: the gods are the perfect mind, their characteristics are the perfect kind of movement; such is the movement in a circle, because it is eternal, has no beginning, no end, and all the time passes into itself. The idea of a circular orbit has entered cosmology for a long time. It was both a progress and a trap at the same time, since the authority of antiquity for a long time did not allow us to look at orbits as other geometric figures. Interest in the ideal geometric figures allowed the Pythagoreans to assume that the Earth and the celestial bodies are celestial. They opened the way to the application of mathematical methods to the knowledge of nature. However, considering heavenly bodies as gods, they missed the opportunity to seek out the natural forces of the motion of the planets. Speculative philosophical discourses on cosmological problems in the history of science outstripped scientific methodology, they outlined the way in which the thought moved, and they sought alternatives and made bold assumptions.

An attempt to synthesize the legacy of the Ionian and Pythagorean cosmology was

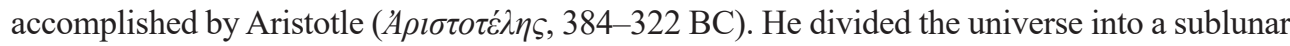
and a supra-lunar region. The world under the Moon of Aristotle is similar to the cosmological teachings of the Ionians, their cosmos is variable, and it consists of four elements - air, fire, earth, and water. This world is changeable and it cannot be described in the language of mathematics. The world above the Moon is eternal and unchanging like the Pythagorean and Platonic ideals of harmony. It is made up of ether - a special kind of matter. Philosopher Valentin Asmus in "Ancient Philosophy" studies questions of philosophy, ethics, aesthetics and cosmology, he writes about Aristotle's ideas: "Aristotle called the fifth physical element "Ether ( $\alpha i \theta \dot{\eta} \rho)$ ". Ether, is an element not only of physics, but of cosmology and the astronomical system of Aristotle. ...Celestial bodies are consisted of ether, and thus the ether fills the world space in which the celestial bodies rotate" [Asmus, 1976: 299]. American physicist, specialist in astrophysics and cosmology Lawrence M. Krauss believes that today the idea of the ether is again relevant because of new discoveries in cosmology: "A decade ago, it seemed to me that dark matter was a sort of modern "fifth essence". But even closer in spirit to Aristotle's heavenly ether or "quintessence" is the currently favored possibility that a nonzero energy exists throughout empty space ... Perhaps nothing in the history of physics resembles more the quintessence of Aristotle than ... [this] vacuum energy, comprising 50-70 \% of the energy density of the universe" [Krauss, 2000: 222-23].

According to Aristotle, each kind of matter corresponds to its natural place in the universe: the earth is in the very center of the world, above are other elements. In the sublunar world, the movement of things is done along vertical straight lines; this movement must have a beginning and an end. If the elements of the sublunary world are taken out of their ordinary place, they will strive to get to their ordinary place. So, if you lift a stone, it naturally falls vertically downward, if you ignite the fire - the flame will rise vertically upwards. When the natural place is reached, the motion of the elements of the sublunary world ceases. All the qualitative changes in the sublunary world were reduced to mechanical movements. The conclusions Aristotle came to 
in his cosmological reflections are: The universe is finite, emptiness does not exist, the Earth is stationary, and the world is one.

It is known that for the first time the idea of heliocentrism in European cosmology was

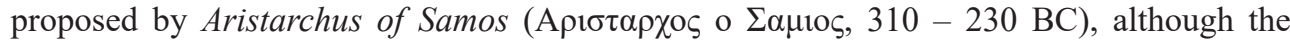
works of the astronomer have not reached our days, we know about his views from texts by

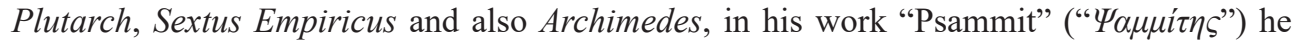
wrote: "But Aristarchus has brought out a book consisting of certain hypotheses, wherein it appears, as a consequence of the assumptions made, that the universe is many times greater than the "universe" just mentioned. His hypotheses are that the fixed stars and the sun remain unmoved, that the earth revolves about the sun on the circumference of a circle, the sun lying in the middle of the orbit, and that the sphere of the fixed stars, situated about the same centre as the sun, is so great that the circle in which he supposes the earth to revolve bears such a proportion to the distance of the fixed stars as the centre of the sphere bears to its surface" [Heath, 2014]. A culmination of ancient cosmology was the creation of the

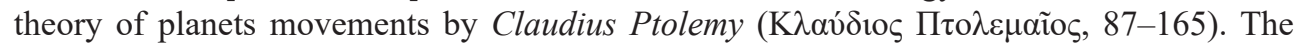
ideas of natural philosophy oh Ptolemy was important to later Byzantine Empire, Islamic and European science.

We have fragmentary ideas about scientific instruments and methods of ancient astronomy, but this does not prevent us from reconstructing cosmological ideas. Ancient Greek scientists also recorded the appearance of comets and covering the planets with the Moon. Therefore, for example, some scientific inventions of antiquity allow us to understand the worldview of that era. The invention of the gnomon, an instrument that allows us to determine the angular altitude of the Sun, indicates an important change in the consciousness of the ancient man. The device, which is able to measure the height of the Sun, changes the idea of the sky, as a place of manifestation of the divine will. The Universe is ruled by a lack of personification necessity. This is the necessity, or debt, of which the ancient Greeks spoke. So Anaximander in the very first fragment of Western philosophy speaks of this necessity: "Whence things have their origin. Thence also their destruction happens, According to necessity; For they give to each other justice and recompense, For their injustice, In conformity with the ordinance of Time" [Curd, 1996: 12]. Among the philosophers there were disagreements about what is outside the Cosmos. Some philosophers believed that there is an infinite empty space; According to Aristotle, outside space there is nothing, not even space; Atomists Leucippus, Democritus and their supporters believed that beyond our world, beyond the sphere of fixed stars are other worlds. The most intriguing were the views of Heraclides Ponticus, according to which fixed stars are other worlds, located in an infinite space.

In the Hellenistic period, new philosophical schools emerged that played a significant role in the development of cosmology. The Epicureans developed the ideas of atomists. Epicureans suggested that in fact, the Earth falls into a kind of world abyss, but we do not notice this fall, as we fall with the Earth. Epicureans claimed the possibility of an infinite number of worlds, similar to ours; these ideas were ahead of their time. In the Roman period, cosmology is gradually approaching to astrology. During this period, many works on physics, philosophy and cosmology are being created. However, the new heyday is replaced by a new crisis, related to the general decline of culture during the collapse of the Roman Empire. Christianity gradually reconsidered the values of ancient civilization.

Middle Ages European astronomers were primarily concerned with observing the visible motions of the planets, coordinating them with the accepted geocentric system of Ptolemy. In the $11-12^{\text {th }}$ centuries, the main scientific works written by the Greeks and their Arab followers 
were translated into Latin. The founder of scholasticism, Albert the Great, and his disciple Thomas Aquinas in the 13th century recomposed Aristotle's teaching, and made it acceptable to the Catholic tradition. From that moment, the Aristotle-Ptolemy system of the Universe actually becomes a Catholic dogmatism. Experimentally based astronomy was replaced by speculative cosmology.

In the $15^{\text {th }}$ century, the German philosopher, Cardinal Nicholas of Cusa (1401-1464), who was much ahead of his time, expressed the opinion that the universe is infinite, and it does not have a center at all - neither the Earth, nor the Sun, nor anything else occupies a special position. All celestial bodies consist of the same matter as the Earth, and, quite possibly, are inhabited. For a century before Galileo, he claimed: all the stars, including the Earth, move in space, and every observer on it can be considered immobile. By the $16^{\text {th }}$ century, it became clear that the Ptolemy system was outdated and leads to errors. Nicolaus Copernicus (Mikołaj Kopernik, 1473-1543) in his main work "On the Revolutions of the Celestial Spheres" ("De revolutionibus orbium coelestium") started the heliocentric revolution in cosmology. He was not the first to suggest heliocentric system of the Universe, but his name became associated with it. In fact, his concept was not strictly heliocentric, since he did not place the sun in the center of the heavenly spheres. At the same time, his concept was full of inaccuracies, for example, orbits were not elliptic in shape but round. Also in his conception, there were celestial spheres.

Innovative and revolutionary cosmological and natural philosophy ideas by Giordano Bruno (the idea of the infinity of the universe and the number of worlds in it, the identification of stars with distant suns, the notion of the material unity of the universe) largely anticipated many of the ideas of modern cosmology. His heliocentric teaching was the important milestone on the way of science development. However, some of the ideas by Giordano Bruno, such as the idea of a general animation of matter, were soon abandoned by science but not abandoned by cosmology.

The study of the history of cosmology, its subject and methods in this article is limited to Antiquity and the Middle Ages, including the Renaissance. In modern times, with the development of scientific methodology, the subject of research has changed. Metaphysics as a science about the ultimate facets of being leaves cosmology behind. Physics, armed with mathematics, is iterated by being, space and the cosmos, deliberately limiting them. Unlike previous cosmologists, a new generation of scientists is looking for the limits of the cosmos, the farthest heavenly body, the highest speed, the brightest object, etc. Despite the fact that the views on the origin of the world and the universe are old, the term "cosmology" (кó "world", " $\lambda \mathrm{o} \gamma 1 \alpha "$ - "doctrine") was introduced in the 18th century by German philosopher Christian von Wolff (Christian Freiherr von Wolff, 1679-1754). Thanks to the popularity of the compendium on metaphysics, written by Wolff in European philosophy, a stable idea of metaphysics was formed as the basis of philosophy. His metaphysical views include ontology, general metaphysics, and disciplines of special metaphysics: theology, psychology and cosmology [Kharitonova, 2013: 7-22]. The ultimate goal of human cognition, according to the philosopher teaching, is the knowledge of God, but the possibility of such knowledge lies in the study of his creations, therefore the science of the Universe - cosmology (empirical physics, rational - metaphysics) - becomes important.

Cosmology arises from the universal science of the Universe and its properties in general, and not about the given Universe, cosmology emerges as a universal science on the one hand and transcendental on the other, which emphasizes the specificity of the subject of cosmology research - not specific objects, but things in general. 


\section{Cosmology in the philosophical education}

In the previous section, the historical change in the subject of the philosophy of cosmology has been described. It has also been shown that there are different views on what to consider as an object of the philosophy of cosmology. Despite of this, the term cosmology is relatively young; the problems of understanding the cosmos have philosophical background. Philosophical methodology allows us to expand the scope of natural science. The analysis of educational materials shows the growing student's interest in the philosophy of cosmology. After the Soviet era, it became possible to study different philosophical trends, and not just Marxism. Previously criticized concepts nowadays received a new consideration. Thus, there are several trends in the study of the philosophy of cosmology:

1. Cosmology is exclusively a section of philosophy, with its problems of being and nothing, of form and matter, of time and space, without the use of mathematics and physics. Thus, the philosophy of cosmology is part of the intellectual culture of humanity in its historical development. Its speculative nature allows us to ask questions, the answers to which are not necessary, the value of such issues lies in themselves. Each era (Antiquity, Middle Ages, New Time, Modernity) is self-sufficient. As the French philosopher Gilles Deleuze and Felix Guattari in the book "What Is Philosophy?" wrote: "Can we say that one plane is "better" than another or, at least, that it does or does not answer to the requirement of the age?" Which means, can one philosophical thought be better than the other? The answer to this question is ambiguous. "Philosophical time is thus a grandiose time of coexistence that does not exclude the before and after but superimposes them in a stratigraphic order" [Deleuze, 1994: 59].

2. The study of cosmology as a division of the history of science and technology. This is partly true, because philosophy emerged as "techne" ( $\tau \dot{\varepsilon} \chi v \eta)$, which translates as art, skill. By "techne" the Greek tradition named the skillful production of something in almost all spheres of human activity, even in such a field as the technique of thought. The term

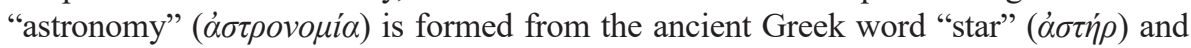
"law" (vó $\mu \circ)$, which means the search for the laws of motion of celestial bodies. In this case, exact mathematical calculations and instruments of observation are required. The etymology of the term "cosmology" is already considered in this article, " $\lambda o \gamma i \alpha$ " is also translated as "word". In the ancient tradition, this concept was introduced by Heraclitus to denote harmony in the Universe. The Logos rules the harmony of the cosmos. Thus, cosmology is a history of science that has lost its relevance and does not carry in itself values for modern science. On the other hand, since the 20th century cosmology has become an independent science of the Universe, its properties and evolution. One of the first works on modern cosmology written by Albert Einstein (1879-1955) marked the beginning of a new history of cosmology "Cosmological Considerations in the General Theory of Relativity" ("Kosmologische Betrachtungen zur allgemeinen Relativitätstheorie", 1917). In it, the author tried to describe the universal system of the Universe, as can be seen from the title of the work.

3. The study of cosmology is not just part of astronomy, but as a competent discipline, that is designed to comprehend the achievements of science by the methods of philosophy. Thus, cosmology is not exclusively a speculative science or creativity of thought, but also does not claim to be a subject of science. Its purpose is to search for the philosophers' perspicacity to explain scientific discoveries. Deleuze wrote that the scientific function and the philosophical concept are not the same [Deleuze, 1994: 22]. Science seeks to find limits, the ultimate speed of light, the moment of the 
beginning of the universe, but philosophy tends to go beyond, to answer the question what was before the beginning and after the end of everything? We talking about "the co-operation between physicists, mathematicians and philosophers in order to identify and explore fundamental issues in cosmology" [Bazaluk, 2013: 8].

Analysis of educational materials, books, monographs and articles shows that the main problems of cosmology have not been finally solved. It can be said that with the emergence of a new mathematical cosmology, interest in its philosophical comprehension arose. So, the main question of science: "what is this?" is supplemented by the question: "what does this mean?" Moreover, new scientific discoveries attract interest in the philosophical views of the past. Different periods of the history of philosophy contain unique cosmological views; this concerns Antiquity, the Middle Ages and the Renaissance. Among the popular studies and textbooks are such books as "Cosmological teachings of early Greek philosophers", 1999, written by historian of philosophy Valentina Bakina Also worth noting historian of philosophy Nikolai Gavryushin and his book "Byzantine cosmology in the 11th century", 1982, philosopher Ivan Lupandin and his discovering of "Aristotelian cosmology and Thomas Aquinas", 1989, also - Edward Grant with "Planets, Stars, and Orbs: The Medieval Cosmos, 1200-1687", 1994. A similar approach to solving the problems of the philosophy of cosmology is proposed by scientists: famous American science historian Lauren $R$. Graham ("Science, Philosophy, and Human Behavior in the Soviet Union", 1987), French philosopher Alexandre Koyré ("From the Closed World to the Infinite Universe", 1957), philosopher Andrei Pavlenko ("Modern cosmology: the problem of justification", 1996), ("European cosmology: the foundations of the epistemological turn", 1997), Tursunov Akbar ("Philosophy and modern cosmology", 1977). Of course, this list is far from complete, it is impossible to list all those who have recently been engaged in the philosophy of cosmology. Great work in the development of this discipline was made by the editors of the scientific journal "Philosophy and Cosmology" which was established by Oleg Bazaluk as a press organ of International Society of Philosophy and Cosmology at 2004. Special merits in the development of the journal belong to philosophers Oleg Khoma and Gennadii Aliaiev. Also worth noting is the work "Introduction to Modern Cosmology", 2013, by authors Sergey Parnovsky, also Irina Mochalova "About two cosmological traditions in the Early Academy", 2007, Boris Frolov "The Number in Archaic Cosmology", 2002.

The book that was published in Cambridge in 2017 is devoted to the problem described in this article - to demonstrate the philosophical aspect of cosmology. The group of authors Khalil Chamcham, Joseph Silk, John D. Barrow, and Simon Saunders published a book for students of higher education institutions, teachers and researchers - "The Philosophy of Cosmology". This book covers topics from Quantum Origin of Cosmological Structure and Dynamical to Limits of Time in Cosmology. There are also several popular books in Western countries: Benjamin Gal-Or ("Cosmology, Physics and Philosophy", 2013), John Leslie ("Physical Cosmology and Philosophy", 1990). Close to our understanding of the philosophy of cosmology came the book of the author Norriss S. Hetherington called "Cosmology: Historical, Literary, Philosophical, Religious and Scientific Perspectives", In this book are being studied the Greeks Geometrical Cosmos, Plato's Cosmology, Aristotle's Cosmology, Ptolemy, Copernicus, Medieval Cosmology and Literature, The Scientific Revolution, Newtonian Cosmology on the one hand and Particle Physics and Cosmology, Large-scale Structure and Galaxy Formation, Cosmic Strings, Quantum Cosmology and the Creation, Cosmology and Philosophy, the Anthropic Principle, Cosmology and Religion from Speculation to Science, the Expanding Universe on the other. 
In the Taras Shevchenko National University of Kyiv, according to the mentioned earlier scientific program of the Philosophical Faculty "Modernization of Philosophical Education and Science of Ukraine on the basis of International Educational and Scientific Standards", was resumed the tradition of teaching a special course "Cosmology in the History of European Philosophy" for students. Western civilization and science are inextricably linked. Comparing Western and Eastern civilization "the development of philosophical ideas and science philosopher [B. Russell] defined the basis of the formation of Western civilization [Bodnarchuk, 2014: 79].

The main task of this educational course is to introduce the student to the main historical facts, texts, and ideas about the structure of space in different historical periods. The task is to demonstrate the significance of cosmological ideas for modern science, their interconnection and complementarity. The discipline consists of two modules: geocentrism in the history of European philosophy and heliocentrism in the history of European philosophy. The first module consists of lectures: Cosmology and cosmogony of "pre-Socratic" philosophers; Cosmological views of Plato and Aristotle; Ptolemy's "Almagest". Mathematical composition in thirteen books; Cosmology of the early and late Middle Ages. The second module consists of lectures: Cosmology of the era of the Scientific Revolution and the Age of Enlightenment; The questions of modern cosmology, modern view of the history of the universe. Together, both modules cover the entire history of cosmological teaching from antiquity to modern times.

In teaching of mentioned discipline, some educational inventions of the scientific department of the philosophical faculty were used. One of them is the computer-based education program. There are several typical problems of teaching philosophical disciplines in higher education of Ukraine: Significantly limited time for such philosophical disciplines, like cosmology which are focused at the formation of general competencies; Lectures are taught for large groups and less of practical classes are arranged; Professors and students are overloaded with paper documents; Professors communication with students is provided only verbally. Therefore, there was a decision to use a productive instrument for solving the problems, and it's e-learning. High efficiency can be reached by using the open-source software Moodle (acronym for modular object-oriented dynamic learning environment). Based on our experience of using software Moodle during 2014-2016 educational years (www.e-philosophy.kiev.ua), there was a decision to use all benefits of e-learning: authorized and controlled access to training course content; monitoring of educational activity of each student; online tests; digital lists of students, academic groups, registers, etc. Thus, the combination of a new course and electronic education has made it possible to create a comprehensive discipline in the study of the philosophy of cosmology.

\section{Conclusion}

From the above we can draw the following conclusions. The subject of the philosophy of cosmology was historically changed; it was understood differently by philosophers from different eras. The term "cosmology" itself is relatively new and arose in the field of philosophy, despite the fact that the ideas of cosmology are very ancient. Therefore, for example, questions of philosophical cosmology can be divided into several groups: 1 . questions of the origin of the cosmos; 2. a question of it's the material and ideal beginning; 3. questions of the future of the cosmos.

The Greeks first proposed a number of hypotheses, which later proved to be very valuable, but it was not possible to verify them. Democritus came up with an atomistic hypothesis matter consists of the smallest atoms, but it was impossible to see them. Only with the 
development of science, after more than two thousand years it turned out that this was the correct scientific point of view. So the philosophical assumption was confirmed by science. However, science needs philosophical reflection. Having ripped out the atom, scientists came to the conclusion that energy is at the heart of matter, and so the unique single substance with different manifestations lies at the basis of our entire Universe, the philosopher Spinoza wrote about it several centuries ago.

Modern science and education is focused on interdisciplinary dialogue, which is one of the conditions for their modernization. Therefore, one can speak of an independent existence of the philosophy of cosmology as a science. In the philosophy of cosmology, we distinguish: first, physical cosmology, which is concerned with the comprehension of mathematical facts, and secondly, metaphysical cosmology, the questions of which go beyond the boundaries of science and seem to be the ultimate foundations of existence; thirdly, it is worth mentioning separately, such as that Contain material for philosophical analysis, religious cosmology, aesthetic cosmology and mystical cosmology. The third kind of philosophical cosmology borders on esotericism and art is not connected with universal science, but with phenomena of the psyche and creative abilities. If physical cosmology is understandable, metaphysical cosmology needs to be clarified. For example, cosmological ideas can vary within the hierarchy of being, can mean hylozoism. "Not only is the prevalence of mental properties in matter, but the existence of a single spiritual center that animates the Universe" [Aliaiev, 2010: 265].

The current state of philosophical cosmology directly depends on interdisciplinary dialogue. In comparison with Western universities and publications, books on philosophical cosmology in Ukraine are few in number. However, as already mentioned, there are positive trends in the modern philosophical community. More and more books are being published, new journals and new communities are opening, and students are becoming more interested in this discipline.

\section{References}

Aliaiev, Gennadii. Christian Cosmology of Vasily Zenkovsky. Philosophy and Cosmology, 2010: 259-270.

Asmus, Valentin. Ancient Philosophy. Moscow: Vysshaya shkola, 1976.

Bakina, Valentina. Cosmological Studies of Early Greek Philosophers. Moscow: Moscow University, 1999.

Bazaluk, Oleg. Universe in the Theoretical Model "Evolving Matter". Philosophy and Cosmology, 2013: 7-11.

Bodnarchuk, Liubov. Comparative Research of Western and Eastern civilizations by Bertrand Russell: the Problem of Human Values. The Multiversum. The Philosophical Almanac. Kyiv, 2014: 78-88.

Curd, Patricia. A Presocratics Reader: Selected Fragments and Testimonia. Indianapolis: Hackett Publishing, 1996.

Danilova, Tatiana. The Desire for recognition in the Context of Francis Fukuyama's Universal History. Anthropological Measurements of Philosophical Research. Vol.10, 2016: 69-77. DOI: https://doi.org/10.15802/ampr.v0i10.87303

Deleuze, Gilles and Félix Guattari. What is Philosophy? London, New York: Verso, 1994.

Gavryushin, Nikolai. Byzantine Cosmology in the $11^{\text {th }}$ Century. Moscow: Science, 1982.

Ginzburg, Vitaly. How the Universe Works and How it Develops in Time. Science and Life, Vol 1-3. Moscow: Editorial Board "Science and Life", 1968. 
Graham, Lauren R. Science, Philosophy, and Human Behavior in the Soviet Union. Moscow: Politizdat, 1987.

Heath, Thomas. Aristarchus of Samos, the Ancient Copernicus. London: Oxford University Press, 1913.

Hetherington, Norriss S. Cosmology: Historical, Literary, Philosophical, Religious and Scientific Perspectives. Boca Raton: CRC Press, 1993.

Kharitonova, Alyona. Machine and body in transcendental cosmology Chr. Wolff and Chr. A. Krusia. Kant's Theoretical Philosophy, Vol. 43. Kaliningrad: Baltic Federal University named after Immanuel Kant, 2013: 7-22.

Khmil, Volodymyr. Ambiguous Janus of Modern Democracy. Anthropological Measurements of Philosophical Research. Vol. 9, 2016: 47-54. DOI: https://doi.org/10.15802/ ampr2016/72228

Khmil, Volodymyr, and Tetiana Khmil. Anthropological aspect of the nature of the state. Anthropological Measurements of Philosophical Research. Vol. 7, 2015: DOI: https://doi. org/10.15802/ampr2015/43374

Koyré, Alexandre. From the Closed World to the Infinite Universe. Moscow: The Logos, 2001.

Krauss, Lawrence. Quintessence: The Mystery of Missing Mass in the Universe. New York: Basic Books, 2000.

Lupandin, Ivan. Aristotelian Cosmology and Thomas Aquinas. In Questions of the History of Natural Science and Technology, Vol. 2. Moscow, 1989: 64-73.

Malivskyi, Anatolii. Anthropological Project as a Basis of Cartesian Ethics. Anthropological Measurements of Philosophical Research. Vol. 11, 2017:117-126. DOI: http:/dx.doi. org/10.15802/ampr.v0i11.105495

Pavlenko, Andrei. European Cosmology: the Foundations of the Epistemological Turn. Moscow: INTRADA, 1997.

Steiner, Rudolf. Cosmology, Religion and Philosophy. London: The Rudolf Steiner Publishing Co, 1943. 